\title{
Histerektomi endikasyonları ve histopatolojik tanıların dağılımı
}

\author{
Hysterectomy indications and distribution of histopathological diagnoses \\ Seda Keskin, Deha Denizhan Keskin*, Özhan Özdemir
}

Kadın Hastalıkları ve Doğum Kliniği (Dr. S. Keskin), Süleymaniye Eğitim ve Araştırma Hastanesi, TR-34020 İstanbul, Kadın Hastalıkları ve Doğum Kliniği (Dr. D. D. Keskin), Bayrampaşa Devlet Hastanesi, TR-34030 İstanbul, Kadın Hastalıkları ve Doğum Kliniği (Dr. Ö. Özdemir), Numune Eğitim ve Araştırma Hastanesi, TR-06100 Ankara

\section{Özet}

Amaç. Kliniğimizde gerçekleştirilen histerektomi operasyonlarının klinik endikasyonlarını incelemek ve histerektomi materyallerindeki histopatolojik tanıları ortaya koymaktır. Yöntem. Ocak 2010-Ocak 2013 tarihleri arasında gerçekleştirilen 223 total abdominal histerektomi olgusu retrospektif olarak incelendi. Yaş, menapozal durum, operasyon endikasyonu, yapılan operasyonun bilgileri ve elde edilen materyalin patolojik inceleme sonuçları analiz edildi. Bulgular. Çalışmaya alınan hastaların yaş ortalaması $49,3 \pm 5,4$ olarak saptandı. Tüm vakalara total abdominal histerektomi uygulanmıştı. Hastaların \%76,2'sine bilateral ooferektomi, \%17,4'üne tek taraflı ooferektomi, \%6,2'sine ise sadece histerektomi uygulanmıştı. Hastaların \%19,2'si menapoz olarak değerlendirildi. Histerektomi endikasyonlarımız arasında en sık izlenen 138 hasta $(\% 61,8)$ ile myoma uteri idi. Diğer endikasyonlar ise sirasıyla 38 hasta (\%17) ile disfonksiyone uterin kanama, 37 hasta $(\% 16,5)$ ile adneksiyel kitle, 10 hasta $(\% 4,4)$ ile pelvik organ prolapsusu idi. Histerektomi materyallerinin histopatolojik incelemesi sonucunda, en yaygin tanımlanan patolojiler sirasiyla \%68,1 , \%37,2, \%18,8 oranlariyla leiomyom, adenomyozis ve overyan/paraoveryan kist olarak belirlendi. En sık görülen kombinasyon \%15,2 ile leiomyom ve adenomyozis kombinasyonuydu. Ayrica 19 hastada $(\% 8,5)$ endometrial polip, 15 hastada $(\% 6,7)$ endometrial hiperplazi, 11 hastada $(\% 4,9)$ atrofik endometrium, 4 hastada $(\% 1,7)$ servikal intraepitelyal neoplazi, 3 hastada $(\% 1,3)$ endometrium kanseri saptandı. Sonuç. Çalışmamızda en sık histerektomi endikasyonu literatürdeki gibi myoma uteri olarak saptand. Histopatolojik inceleme sonucunda ise en sık leiomyom ve adenomyozis saptand. Menometroraji/pelvik ağrı şikayeti ile başvuran ve özellikle myoma uterisi olan hastalarda eşlik eden adenomyozis olabileceği akılda tutulmalıdır. Fertilitesini tamamlamış perimenapozal ve postmenapozal kadınlarda gerek pelvik ağrı, gerekse menometrorajiye sebep olan myomların tedavisinde halen en fazla histerektomi tercih edilmektedir.

Anahtar sözcükler: Histerektomi, histopatoloji, leiomyom, adenomyozis

\begin{abstract}
Aim. Examine the clinical indications for hysterectomy operations performed in our clinic and put forward the histopathologic diagnosis of hysterectomy materials. Method. 223 total abdominal hysterectomy cases performed between January 2010-January 2013 were retrospectively evaluated. Age, menopausal status, operation indication, the operation data and the results of materials pathological examination were analyzed. Results. The mean age of the patients was 49.3 \pm 5.4 . All cases underwent total abdominal hysterectomy. $76.2 \%$ of the patients was performed bilateral oopherectomy, $17.4 \%$ of the patients was performed unilateral oopherectomy, $6.2 \%$ of the patients was performed only hysterectomy. Between the hysterectomy indications the most common one was leiyomyom with 138 patients $(61.8 \%)$. The other indications were dysfunctional uterine bleeding with 38 patients (17\%), adnexal masses with 37 patients (16.5\%), pelvic organ prolapse with 10 patients $(4.4 \%)$. As the result of histopathological examinations of hysterectomy materials, the most common pathologies are defined as leiomyom, adenomyosis, and ovarian/paraovarian cyst with the rates $68.1 \%, 37.2 \%, 18.8 \%$, respectively. The most common combination was leiomyom and adenomyosis combination with the ratio of $15.2 \%$. In addition, 19 patients $(8.5 \%)$ were determined with endometrial polyps, 15 patients $(6.7 \%)$ with endometrial hyperplasia, 11 patients $(4.9 \%)$ with atrophic endometrium, 4 patients $(1.7 \%)$ with cervical intraepithelial neoplasia, 3 patients $(1.3 \%)$ with endometrial cancer. Conclusion. In our study, the most common indication of hysterectomy was uterine myoma as the literature. The most common histopathological examination result was leiomyom and adenomyosis. Adenomyosis must be kept
\end{abstract}


in mind in patients who consulted with complaint of menometrorrhagia/ pelvic pain and especially having myoma. Hysterectomy is the most preferred choice in treatment of pelvic pain and also myomas causing menometrorrhagia in perimenopausal with no further desire of childbearing and postmenopausal women.

Keywords: Hysterectomy, histopathology, leiomyom, adenomyosis

Geliş tarihi/Received: 15 Mart 2013; Kabul tarihi/Accepted: 24 Haziran 2013

\section{*İletișim adresi:}

Dr. Deha Denizhan Keskin, Kadın Hastalıkları ve Doğum Kliniği, Bayrampaşa Devlet Hastanesi, TR-34030 İstanbul. E-posta: dehara@ mynet.com

*Bu çalışma 15-19 Mayıs 2013’te Antalya'da gerçekleştirilen 11. Ulusal Jinekoloji ve Obstetrik Kongresi'nde poster bildiri olarak kabul edilmiştir.

\section{Giriş}

Histerektomi sezaryenden sonra en sık yapılan ikinci jinekolojik cerrahi işlemdir [1]. Histerektomi uygulanan cerrahi sahasına göre abdominal veya vajinal yoldan, laparotomi veya laparoskopi tekniği kullanılarak uygulanabilir. Total abdominal histerektomi ve bilateral salpingoooferektomi operasyonu ilk olarak 1844 y1lında Clay [2] tarafindan yapılmıştır. Histerektomi çok çeşitli jinekolojik ve obstetrik nedenlere bağlı gerçekleştirilse de tüm dünyada uterin myomlar histerektominin en s1k endikasyonudur [1]. Bir çok çalışmaya göre histerektomilerin büyük çoğunluğu 40-55 yaş arasında gerçekleşmektedir [3]. Çeşitli araştırmalarda 60 yaşına kadar yaklaşık dört kadından birine, 65 yaşına ulaşan her üç kadından birine histerektomi yapılacağı hesaplanmıştır [4, 5]. Uygulanacak histerektomi tekniğini belirlemede; operasyonun endikasyonu, hastanın tercihi, kondüsyonu, cerrahın eğitim ve deneyimi göz önünde tutulmalıdır [6]. Histerektomiyle beraber salpingooferektomi uygulanması, hastanın yaşı, endikasyonu, menapozal durumu, yaşam beklentisi ile yakından ilişkilidir. Elektif bilateral salpingooferektomi yapılması ileride oluşma potansiyeli bulunan tuba ve over kanser riskini ortadan kaldırmaktadır [7, 8]. Ancak bunun yanında menapozun getirdiği osteoporoz ve kardiyovasküler riskler artmaktadır [9-12].

\section{Gereç ve yöntem}

Ocak 2010-Ocak 2013 tarihleri arasında gerçekleştirilen 223 histerektomi operasyonunun bilgilerine ulaşıldı. Yaş, menapozal durum, operasyon endikasyonu, yapılan operasyonun bilgileri ve elde edilen materyalin patolojik inceleme sonuçları analiz edildi. Hastalar endikasyonlarına göre; myoma uteri (Kronik pelvik ağrı oluşturan, anormal uterin kanamaya sebep olan), disfonksiyone uterin kanama, adneksiyel kitle, pelvik organ prolapsusu olarak gruplara ayrıld1. Histopatolojik tanılar leiomyom, adenomyozis, overyan/paraoveryan kist, endometrial polip, atrofik endometrium, endometrial hiperplazi, endometrium kanseri, servikal intraepitelyal neoplazi olarak sinıflandi. Veriler ortalama ve standart hata ile yüzde olarak sunuldu.

\section{Bulgular}

Ocak 2010-Ocak 2013 tarihleri arasında gerçekleştirilen 223 histerektomi operasyonu çalışmaya dahil edildi. Histerektomi uygulanan en genç hasta 38, en yaşlı hasta 71 yaşında idi. Yaş ortalaması ise 49,3 $\pm 5,4$ olarak saptandı. Hastaların \%19,2'si (43/223) menapoz olarak değerlendirildi. Hastaların \%76,2'sine bilateral ooferektomi, \%17,4'üne ise tek taraflı ooferektomi uyguland. Hastaların \%6,2'sinde ise sadece histerektomi uyguland. En s1k histerektomi endikasyonu 138 hasta $(\% 61,8)$ ile myoma uteri idi. Diğer endikasyonlar ise surasiyla 38 hasta (\%17) ile disfonksiyone uterin kanama, 37 hasta $(\% 16,5)$ ile adneksiyel kitle, 10 hasta $(\% 4,4)$ ile pelvik organ prolapsusu idi. Myom olgularının \%42,75 sinde anormal uterin kanama, \%57,25'inde kronik pelvik ağrı mevcuttu (Tablo 1). 
Tablo 1. Histerektomilerin klinik endikasyonları.

\begin{tabular}{lll}
\hline & Hasta sayısı (n) & Görülme oranı (\%) \\
\hline Myom & 138 & $\% 61,8$ \\
Disfonksiyone uterin kanama & 38 & $\% 17$ \\
Adneksiyel kitle & 37 & $\% 16,5$ \\
Pelvik organ prolapsusu & 10 & $\% 4,4$ \\
\hline
\end{tabular}

Histerektomi materyallerinin histopatolojik incelemesi sonucunda, en yaygin tanımlanan patolojiler sirasiyla \%67,7 (151/223), \%37,2 (83/223), \%18,8 (42/223) oranlarıly leiomyom, adenomyozis ve overyan/paraoveryan kist olarak belirlendi. Hastaların $\% 29,5$ 'inde bu üç tanının kombinasyonları bulunmakta idi. En sık görülen kombinasyon $\% 15,2$ (34/223) ile leiomyom ve adenomyozis kombinasyonuydu. Ayrica 19 hastada $(\% 8,5)$ endometrial polip, 15 hastada $(\% 6,7)$ endometrial hiperplazi, 11 hastada $(\% 4,9)$ atrofik endometrium, 4 hastada $(\% 1,7)$ servikal intraepitelyal lezyon, 3 hastada $(\% 1,3)$ endometrium kanseri saptandı. Çalışmadaki endometrial hiperplazilerin çoğu basit atipisiz iken sadece bir hastada kompleks atipisiz hiperplaziye rastlandı. Servikal intraepitelyal lezyonlardan üçü hafif, biri orta derecede displazik idi (Tablo 2).

Tablo 2. Histerektomi materyallerinin histopatolojik incelemesi sonuçları.

\begin{tabular}{lll}
\hline & Hasta sayısı (n) & Görülme oranı (\%) \\
\hline Leiomyoma uteri & 151 & $\% 67,7$ \\
Adenomyozis & 83 & $\% 37,2$ \\
Overyan/paraoveryan kist & 42 & $\% 18,8$ \\
Endometrial polip & 19 & $\% 8,5$ \\
Endometrial hiperplazi & 15 & $\% 6,7$ \\
Atrofik endometrium & 11 & $\% 4,9$ \\
Servikal intraepitalyal neoplazi & 4 & $\% 1,7$ \\
Endometrium kanseri & 3 & $\% 1,3$ \\
Leioyomyosarkom & 1 & $\% 0,4$ \\
Kombine patolojiler & 65 & $\% 29,5$ \\
\hline
\end{tabular}

Menometroraji şikayeti olan 57 yaşındaki myoma uteri tanısıyla opere edilen hastada eksize edilen kitlenin leiomyosarkom olduğu histopatolojik inceleme sonucu öğrenildi. Overyan/paraoveryan kist histopatolojisi olan hastalar ayrıca incelendi. (Tablo3) Hiçbir vakada ileri kanser cerrahisini gerektirecek malign bir patolojiye rastlanmadi. 44 yaşında myom ve adneksiyel kitle nedeniyle opere edilen bir hastada ise over torsiyonu saptandi. Kronik pelvik ağrı şikayeti ile başvuran postmenapozal üç hastaya myom uteri tanısıyla histerektomi uyguland1. Preoperatif endometrial örnekleme uygulanmayan bu hastaların histopatolojik incelemelerinde endometrium kanseri saptand1.

Tablo 3. Overyan/paraoveryan kistlerin ayrıntılı histopatolojik incelemesi sonuçları.

\begin{tabular}{lll}
\hline & Hasta sayısı (n) & Tüm piyeslerindeki oranı (\%) \\
\hline Seröz kist & 16 & $\% 7,2$ \\
Müsinöz kist & 4 & $\% 1,8$ \\
Endometrioma & 7 & $\% 3,1$ \\
Dermoid kist & 4 & $\% 1,8$ \\
Fibroma/Tekoma & 3 & $\% 1,3$ \\
Paratubal kist & 8 & $\% 3,6$ \\
\hline
\end{tabular}

\section{Tartışma}

Histerektomi sezaryendan sonra kadın doğum hekimlerince uygulanan en s1k ikinci cerrahi işlemdir. Perimenapozal ve postmenapozal dönemde ise en sık uygulanan cerrahidir. Histerektominin endikasyonları oldukça geniştir [2]. Çalışmamızda histerektomi literatürlere benzer şekilde en sık 45-55 yaş arasındaki hastalara uygulandi. Histerektomi endikasyonları 138 hasta $(\% 61,8)$ ile myoma uteri, 38 hasta $(\% 17)$ ile 
disfonksiyone uterin kanama, 37 hasta $(\% 16,5)$ ile adneksiyel kitle, 10 hasta $(\% 4,4)$ ile pelvik organ prolapsusu idi. Tazegül ve ark. [13] tarafından yapılan çalışmada en sık histerektomi endikasyonu \%41,9 ile myoma uteri, \%18,8 ile jinekolojik maligniteler olarak bulunmuştur. 1,7 milyon olgunun retrospektif olarak incelendiği çalışmada, histerektomi endikasyonlarının \%30'unu myoma uteri, \%20'sini endometriozis, $\% 18,2$ 'sini endometrium kanseri ve endometrial hiperplazi, \%17,5'ini uterin prolapsus oluşturmaktadır [14]. 1885 vakalık bir çalışmada, histerektomilerin \%38,5'inin myoma, $\% 35,3$ 'ünün disfonksiyonel uterin kanama, \%6,5'inin prolapsus uteri, \%5,6'sının invaziv ve preinvaziv maligniteler nedeniyle yapıldığı gösterilmiştir [8]. Maresh [15] çalışmasında, en sık histerektomi endikasyonunun \%46 ile disfonksiyonel uterin kanama olduğu gösterilmiştir. Çalışmamızda histerektomi endikasyonu olarak myom uteri literatürden daha yüksek saptanmıştır. Biz bunu endometrium kanseri gibi malign vakaları üst merkeze refere etmemize ve menometroraji ve pelvik ağrı etyolojisinin araştırılmasında ultrasonu oldukça etkin olarak kullanmamıza bağladık. Çalışmamızda disfonksiyone uterin kanama endikasyonuları ise literatüre göre daha azd1. Kliniğimizde endometrial biyopsi ile maligniteyi ekarte ettiğimiz disfonksiyone uterin kanamalı hastalara genel yaklaşımımız öncelikle medikal tedavi olmaktadır. Medikal tedaviye dirençli olgularda cerrahiyi tercih etmemizin bu sonucu yarattığını düşünüyoruz.

Bir çalışmada 100 histerektomi materyali incelenmiş ve şu sonuçlar elde edilmiştir. Histopatoloji piyeslerinde 38 vakada myoma ve adenomyosis, 25 vakada myoma uteri, 3 olguda adenomyosis saptanmıştır [16]. Toplam 621 histerektomi materyalinin incelendiği bir başka çalışmada \%44,76 leiomyom, \%22,33 endometrial hiperplazi, \%14 adenomyozis, \%12,23 malignite, \%6,44 endometriozis tespit edilmiştir [17]. Diğer bir çalışmada \%17,07 leiomyom, \%3,96 adenomyozis, \%3,35 endometrit, \%2,44 serviks karsinomu, \%2,44 endometrial polip, \%1,83 endometrial hiperplazi saptanmıştır [18]. Bizim çalışmamızda leiomyom \%67,7, adenomyozis \%37,2, ikili kombinasyonu \%15,2 oranında görüldü. Malign ve malignite potansiyeli fazla olan vakaların bir üst merkeze refere edilmesine bağlı olarak leiomyom ve adenomyozis gibi benign vakaların patoloji piyeslerinde daha fazla saptandığını düşünüyoruz. Endometrial hiperplazi ise literatüre oranla oldukça düşük saptanmıştır. Çünkü atipisiz endometrial hiperplazi olgularında daha çok medikal tedaviyi tercih etmekteyiz.

Adenomyozisin etyolojisi ve patolojik mekanizması tam olarak bilinmemekle beraber histopatolojik tanı oranları patologlar arasında \%10 ile \%80 arasında değişmektedir [1923]. Bazı çalışmalarda histerektomi materyallerinde adenomyozis sıklığının \%5-70 arasında değişiklik gösterdiğini bildirmiştir [24]. Bizim çalışmamızda adenomyozis \%37,2 olarak saptanmıştır.

Endometrial polipler anormal uterin kanamanın en sik görülen nedenidir. Genel populasyonda yaklaşık olarak \%15-25 oranında olduğu tahmin edilmektedir [25-27]. Bizim çalışmamızda endometrial polip görülme oran1 \%8,5 idi. Endometrial poliplerin tedavisinde $\mathrm{D} \& \mathrm{C}$ ve histeroskopik rezeksiyonu tercih ettiğimizden dolayı piyeslerde daha az endometrial polip saptandığını düşünüyoruz.

Benign nedenlerle yapılan 1832 histerektomi materyalinin patoloji sonucunun incelendiği çalışmada leiyomyosarkom saptanma oranı \%0,81 olarak saptanmıştır [28]. Bizim çalışmamızda benign ön tanılarla operasyon yapılmasına rağmen leiomyosarkom oranı $\% 0,44$ olarak saptanmıştır.

Myom uteri nedeniyle histerektomi planlanan hastalarda endometrial örneklemenin gerekliliğini araştıran pek çok çalışma vardır. Stock örneklemenin gerektiğini ancak vakaların yarıdan çoğunda değerlendirmenin yetersiz olduğunu savunmaktadır [29]. Lerner çalışmasında endometrium kanserini \%2,8 olarak saptamış ve bu vakaların sadece \%20'sinde D\&C sonuçlarında patoloji saptanmıştır. Çalışmacı bu yüzden rutin örneklemeyi önermemektedir [30]. Stovall [31] ise örneklemenin sadece 35 yaş üstü anormal uterin kanama ile başvuran hastalara yapılması gerektiğini savunmaktadır. Bizim 
çalışmamızda endometrium kanseri \%1,3 olarak saptandı. Endometrium kanseri saptanan üç hasta pelvik ağrı nedeniyle başvuran myoma uterisi olan hastalardı. Yüksek risk grubunda olmadığı için prehisterektomi örnekleme yapmadığımız hastalarda histopatoloji sonuçları erken evre endometrium kanseri olduğundan ikinci cerrahiyi gerektirmemiştir.

Sonuç olarak; histerektomi endikasyonları oldukça geniş olup literatürde oldukça farklı oranlar göze çarpmaktadır. Çalışmamızda en sık histerektomi endikasyonu \%61,8 ile myoma uteri olarak saptand. Histopatolojik inceleme sonucunda ise vakaların $\% 67,7$ 'inde leiomyoma uteri, $\% 37,2$ 'inde adenomyozis, $\% 18,8$ 'inde overyan/paraoveryan kist saptandi. Disfonksiyone uterin kanamalardaki medikal tedavi seçenekleri, adneksiyel kitlelerde hasta arzusuyla uterus koruyucu cerrahinin uygulanması, endometrial polip tedavisinde histeroskopinin ve D\&C'nin kullanılması, endometrial hiperplazilerde medikal tedavinin tercih edilmesi gibi nedenlerle diğer histopatolojik sonuçların daha az olduğunu düşünmekteyiz. Fertilitesini tamamlamış perimenapozal ve postmenapozal hasta grubunda gerek pelvik ağrı, gerekse menometrorajiye sebep olan myomların tedavisinde halen en uygun seçeneğin histerektomi olduğunu düşünmekteyiz.

\section{Kaynaklar}

1. Rock JA, Jones HW III, Histerektomi, In: Te Linde's Operatif Jinekoloji 9. Basım, Çeviri Editörü: Erol Tavmergen, İzmir Güven Kitabevi 2005; 31: 731-55.

2. Coulter A, Bradlow J, Agass M, Martin-Bates C, Tulloch A. Outcomes of referrals to gynaecology outpatient clinics for menstrual problems: An audit of general practice records. Br J Obstet Gynaecol 1991; 98: 789-96.

3. Davies A, Magos AL. Indications and alternatives to hysterectomy. Baillieres Clin Obstet Gynaecol 1997; 11: 61-75.

4. Bren L. Alternatives to hysterectomy. New technologies, more options. FDA Consum. 2001; 35: 23-8.

5. Marana R, Busacca M, Zupi E, Garcea N, Paparella P, Catalano GF. Laparoscopically assisted vaginal hysterectomy versus total abdominal hysterectomy: A prospective, randomized, multicenter study. Am J Obstet Gynecol 1999; 180: 270-5.

6. Kovac SR, Barhan S, Lister M, Tucker L, Bishop M, Das A. Guidelines for the selection of the route of hysterectomy: application in a resident clinic population. Am J Obstet Gynecol 2002; 187: 1521-7.

7. Speroff T, Dawson NV, Speroff L, Haber RJ. A risk-benefit analysis of elective bilateral oophorectomy: effect of changes in compliance with estrogen therapy on outcome. Am J Obstet Gynecol 1991; 164: 165-74.

8. Vessey MP, Villard-Mackintosh L, McPherson K, Coulter A, Yeates D. The epidemiology of hysterectomy: Findings in a large cohort study. British J Obstet Gynecol 1992; 99: 402-7.

9. Dicker RC, Greenspan JR, Strauss LT, Cowart MR, Scally MJ, Peterson HB, DeStefano F, Rubin GL, Ory HW. Complications of abdominal and vaginal hysterectomy among women of reproductive age in the United States. The Collaborative Review of Sterilization. Am J Obstet Gynecol 1982; 144: 841-8.

10. García CR, Cutler WB. Preservation of the ovary: A reevaluation. Fertil Steril 1984; 42: 510-4.

11. Grundsell H, Ekman G, Gullberg B, Johnsson JE, Larsson G, Lindahl B, Möller T, Trope C. Some aspects of prophylactic oophorectomy and ovarian carcinoma. Ann Chir Gynaecol 1981; 70: 36-42.

12. Cole P, Berlin J. Elective hysterectomy. Am J Ostet Gynecol 1977; 129: 177-23.

13. Tazegül A, Acar A. Kliniğimizde Gerçekleştirilen Histerektomi Olgularının Klinik ve Demografik Özelliklerinin Değerlendirilmesi. Selçuk Tıp Dergisi 2010; 26: 19-22.

14. Wilcox LS, Koonin LM, Pokras R, Strauss LT, Xia Z, Peterson HB. Hysterectomy in the United States, 1988-1990. Obstet Gynecol 1994; 83: 549-55. 
15. Maresh MJ, Metcalfe MA, McPherson K, Overton C, Hall V, Hargreaves J, Bridgman S, Dobbins J, Casbard A. The value national hysterectomy study: Description of the patients and their. BJOG 2002; 109: 302-12.

16. Shergill SK, Shergill HK, Gupta M, Kaur S. Clinicopathological study of hysterectomies. J Indian Med Assoc 2002; 100: 238-9.

17. Ojeda VJ. The pathology of hysterectomy specimens. Z Med J 1979; 89: 169-71.

18. Talukder SI, Haque MA, Huq MH, Alam MO, Roushan A, Noor Z, Nahar K. Histopathological analysis of hysterectomy specimens. Mymensing Med J 2007; 16: 81-4.

19. Arif A, Jamal S, Mubarik A, Zubair A, Ghori UK. Study of adenomyosis in different decades of life: An experience at army medical college, RawalpindiPakistan. Pak J Pathol 2007; 18: 75-8.

20. Lee NC, Dicker RC, Rubin GL, Ory HW. Confirmation of the preoperative diagnoses for hysterectomy. Am J Obstet Gynecol 1984; 150: 283-7.

21. Ferenczy A. Pathophysiology of adenomyosis. Hum Reprod Update 1998; 4: 312-22.

22. Leyendecker G, Wildt L, Mall G. The pathophysiology of endometriosis and adenomyosis: Tissue injury and repair. Arch Gynecol Obstet 2009; 280: 529-38.

23. Bird CC, McElin TW, Manalo-Estrella P. The elusive adenomyosis of the uterus-revisited. Am J Obstet Gynecol 1972; 112: 583-93.

24. Kitawaki J. Adenomyosis: the pathophysiology of an oestrogen-dependent disease. Best Pract Res Clin Obstet Gynecol 2006; 20: 493-502.

25. Sherman ME, Mazur MT, Kurman RJ. Benign diseases of the endometrium. In: Kurman RJ, editor. Blaunstein's pathology of the female genital tract. 5. edition. New York: Springer 2002; 421-66.

26. Perez-Medina T, Martinez O, Folgueira G, Bajo J. Which endometrial polyps should be resected? J Am Assoc Gynecol Laparosc 1999; 6: 71-4.

27. Reslova T, Tosner J, Resl M, Kugler R, Vavrova I. Endometrial polyps. A clinical study of 245 cases. Arch Gynecol Obstet 1999; 262: 133-9.

28. Bukhari U, Sadiq S. Analysis of the underlying pathological lesions in hysterectomy specimens. Pak J Pathol 2007; 18: 110-2.

29. Stock RJ, Kanbour A. Prehysterectomy curretage. Obstet Gynecol 1975; 45: 53741.

30. Lerner HM. Lack of efficacy of prehysterectomy curettage as a diagnostic procedure. Am J Obstet Gynecol 1984; 148: 1055-6.

31. Stovall TG, Soloman SK, Ling FW. Endometrial sampling prior to hysterectomy. Obstet Gynecol 1989; 73:405-9. 